\title{
Determination of Serum Adiponectin Levels in Normal Weight Women with Polycystic Ovary Syndrome
}

\author{
Rana A. Hamdi * \\ Nawar S. Mohammed* \\ Afraa M. AL-Naddawi **
}

\author{
MSc in clinical biochemistry, \\ MSc in clinical biochemistry, \\ MBChB, CABOG, FIBOG
}

Abstract:

Background: Polycystic ovary syndrome (PCOS) is a common endocrine disorder in women of reproductive age with primary manifestations of infertility, menstrual dysfunction and clinical or biochemical hyperandrogenism (hirsutism, acne and elevated androgen).

Adiponectin is the most abundant adipokine. It has insulin-sensitizing, anti-atherogenic, and antiinflammatory actions.

Objective: Low adiponectin levels in women with PCOS have been largely attributed to obesity which is common among these patients. Therefore, the aim of this study was to measure adiponectin levels in normal weight women with PCOS and its contribution to development of disease.

Fac Med Baghdad 2015; Vol.57, No.2 Received:Feb., 2015 Accepted:March,2015
Subjects and Methods: Fifty two (52) women were included in this study with age range (21-34 years). Subjects were divided into two groups: group A: twenty seven (27) women with PCOS and group B: twenty five (25) women without PCOS (serve as controls). PCOS can be diagnosed when two of the three following criteria are present (oligoovulation and/or anovulation, clinical and/or biochemical hyperandrogenism and polycystic ovaries as defined by ultrasonography).

Results: Mean serum adiponectin level was significantly lower in women with PCOS comparing to those BMI-matched controls $(\mathrm{P}=0.000)$.

Conclusion:Serum adiponectin levels are not independently determined by the degree of obesity in women but underlying disease may also have some role and this may due to insulin resistance in these patients thus determining serum adiponectin may serve as a useful marker in detecting cases of normal weight women with PCOS.

Keywords: Polycystic ovary syndrome, insulin resistance, adiponectin.

\section{Introduction:}

Polycystic ovary syndrome (PCOS) is a common endocrine disorder in women of reproductive age with primary manifestations of infertility, menstrual dysfunction and clinical or biochemical hyperandrogenism (hirsutism, acne and elevated androgen) (1).

Polycystic ovary syndrome affects about 7 to $8 \%$ of women and may be the most common cause of anovulation, early pregnancy loss, and later pregnancy complications. All have been implicated in the low fecundity of women with this disorder (2).

Insulin resistance (IR) has been considered to be the most important aetiological aspect of the reproductive and metabolic abnormalities in PCOS $(3,4)$.

Adipose tissue is an active endocrine organ, by releasing a variety of bioactive peptides and adipokines, modulate body's metabolism at local and systemic levels (5). The production of adipokines has been shown to affect insulin sensitivity and to be an important predictor of the metabolic syndrome (6).

*Corresponding Auther: Rana A. Hamdi. rana.

chemist2006@yahoo.com

Dept. of Biochemistry, Collage of Medicine, University of Baghdad

** Dept. of Obstetrics and Gynecology, Collage of Medicine, University of Baghdad.
Adiponectin is the most abundant adipokines and is mainly secreted from visceral fat cells (7).

Adiponectin is a protein of 247 amino acids consisting of four domains, with a molecular weight of $30 \mathrm{kDa}$, and it has insulinsensitizing $(8,9)$, anti-atherogenic (10), and anti-inflammatory actions (11).

Also adiponectin modulates a number of metabolic processes, including glucose regulation and fatty acid oxidation (12).

In vitro and in vivo studies have shown that adiponectin has beneficial effects on the reproductive processes and an important relationship with the gonadotropins and other hormones (13-15).

\section{Subjects and Methods:}

Fifty two (52) women were included in this study with age range (21-34 years). Women were attended to obstetric and gynecology outpatient clinic in Baghdad Teaching Hospital during the period from December 2014 to January 2015. Subjects were divided into two groups: group A: twenty (27) women with PCOS and group B: twenty five (25) women without PCOS (serve as controls).

PCOS can be diagnosed when two of the three following criteria are present (oligoovulation and/or anovulation, clinical 
and/or biochemical hyperandrogenism and polycystic ovaries as defined by ultrasonography). PCOS can be diagnosed after the exclusion of other medical conditions and if she fulfilled 2 out of 3 criteria mentioned above.

Exclusion criteria included hyperprolactinemia, diabetes mellitus, impaired thyroid, renal or hepatic function and subjects treated with drugs known to influence insulin sensitivity (e.g., steroids, oral contraceptives, metformin, or thiazide diuretics).

Serum investigations included fasting blood glucose which was measured by spectrophotometer, testosterone was measured by minividas, fasting serum insulin was measured by enzyme linked immuno sorbent assay (ELISA), Adiponectin measured by ELISA using kit manufactured by (MBL International Corporation), and homeostasis model assessment of insulin resistance (HOMA- IR) calculates the IR by dividing the product of fasting blood glucose level ( $\mathrm{mg} / \mathrm{dl})$ and serum insulin level $(\mu \mathrm{U} / \mathrm{ml})$ by a constant, i.e. 405 . A HOMA-IR value of 2.5 or above were considered as insulin resistant (16).

In addition body mass index (BMI) was calculated as weight in kilograms per height (square meter) [weight/ (height) ${ }^{2}$, women were considered as normal weight at BMI (18.5-24.9 $\left.\mathrm{kg} / \mathrm{m}^{2}\right)$, overweight women $\left(25-29.9 \mathrm{~kg} / \mathrm{m}^{2}\right)$ and obese women at $\mathrm{BMI}>30 \mathrm{~kg} / \mathrm{m}^{2}(17)$.

\section{Statistical analysis:}

Data were analyzed using computer facility of SPSS-17 (Statistical Package for Social Science - version 17). The results were expressed as numbers, range and mean \pm SD (standard deviation). Significance of difference was assessed using Student-t test for two independent means.

Results:

Patients and controls were matching for age and body mass index (BMI), there were no significant difference in serum glucose levels between patients and controls but there were significant increase in serum total testosterone levels, serum insulin levels, HOMA in patients comparing to controls. In addition serum adiponectin levels were significantly decreased in patients compared to that of controls (Table 1).

Table (2) shows the quartile of serum adiponectin levels for patients and controls. This type of statistic give idea about upper (Q3) and lower (Q1) limit of serum adiponectin levels, $\%$ of Q1,Q3 and between Q1-Q3 with number of patients and controls in each group.

Table (1): Mean value of age, BMI, serum total testosterone, serum glucose, serum insulin, HOMA and serum adiponectin levels for patients and controls.

\begin{tabular}{|c|c|c|c|c|c|}
\hline \multirow{2}{*}{ Parameters } & \multicolumn{2}{|c|}{ Patients $(n=27)$} & \multicolumn{2}{|c|}{ Controls $(n=25)$} & \multirow{2}{*}{ P value } \\
\hline & Mean \pm SD & Range & Mean \pm SD & Range & \\
\hline Age (years) & $27.18 \pm 3.51$ & $(22-34)$ & $26.92 \pm 3.94$ & $(21-33)$ & $0.86(\mathrm{NS})$ \\
\hline BMI $\left(\mathrm{Kg} / \mathrm{m}^{2}\right)$ & $23.31 \pm 1.21$ & $(20.13-24.61)$ & $23.12 \pm 0.92$ & $(20.86-24.32)$ & $0.68(\mathrm{NS})$ \\
\hline $\begin{array}{c}\text { Total testosterone } \\
\text { Normal }(0.1-0.9 \mathrm{ng} / \mathrm{ml}) \\
\end{array}$ & $3.61 \pm 1.05$ & $(1.44-5.39)$ & $0.45 \pm 0.13$ & $(0.29-0.76)$ & $0.000(S)$ \\
\hline $\begin{array}{c}\text { Serum insulin } \\
\text { Normal }(2-25 \mu \mathrm{IU} / \mathrm{ml})\end{array}$ & $29.52 \pm 2.18$ & (26.94-33.86) & $10.46 \pm 1.09$ & $(8.12-12.31)$ & $0.000(\mathbf{S})$ \\
\hline Serum glucose Normal(65-110 mg/ml) & $83.48 \pm 3.58$ & $(81-95)$ & $82.28 \pm 3.49$ & (76-88) & $0.38(\mathrm{NS})$ \\
\hline HOMA Normal $<2.5$ & $6.08 \pm 0.48$ & $(5.38-7.14)$ & $2.12 \pm 0.19$ & $(1.68-2.39)$ & $0.000(S)$ \\
\hline Serum adiponectin (ng/ml) & $13.27 \pm 1.9$ & $(8.85-15.9)$ & $19.23 \pm 1.81$ & $(16.55-22.24)$ & $0.000(S)$ \\
\hline
\end{tabular}

$\overline{\mathrm{S}}=$ significant, $\mathrm{NS}=$ non-significant

Table (2): Quartiles of serum adiponectin levels for patients and controls.

\begin{tabular}{|c|c|c|c|c|}
\hline \multirow{2}{*}{ Adiponectin } & \multicolumn{2}{|c|}{ Patients $(n=27)$} & \multicolumn{2}{|c|}{ Controls (n=25) } \\
\hline & No. & $\%$ & No. & $\%$ \\
\hline$<$ Q1 $(<12.06)$ & 6 & $22.22 \%$ & 5 & $22.73 \%$ \\
\hline Q1-Q3 (12.06-14.08) & 16 & $59.26 \%$ & 11 & $50 \%$ \\
\hline$>Q 3(>14.08)$ & 5 & $18.52 \%$ & 6 & $27.27 \%$ \\
\hline
\end{tabular}




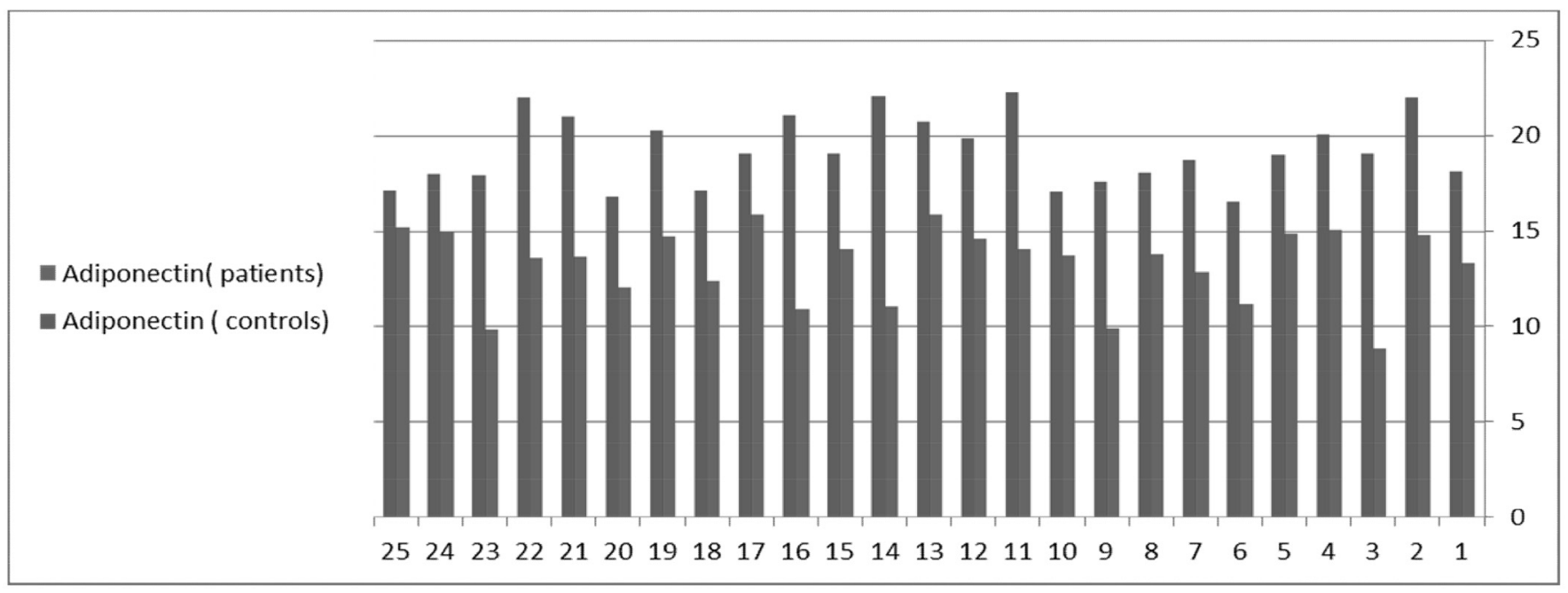

Figure (1): Serum adiponectin levels in patients and controls.

\section{Discussion:}

PCOS is an important metabolic and reproductive disorder and is likely multifactorial in origin. Insulin resistance is important in the pathogenesis of PCOS $\square$ (18). The "central paradox" in PCOS is that the ovary remains sensitive to insulin-induced androgen production despite a systemic insulin-resistant state. The serine phosphorylation theory may explain this paradox. Serine phosphorylation of the insulin receptor inhibits tyrosine kinase activity of the receptor, and this defect in insulinsignaling causes insulin resistance in women with PCOS (19). Serine phosphorylation of the main regulatory enzyme of androgen biosynthesis, P450c17, may modulate 17, 20 lyase activity and induce androgen production. This hypothesis suggests that a single kinase might phosphorylate the insulin receptor and $\mathrm{P} 450 \mathrm{c} 17$ to produce hyperandrogenemia and hyperinsulinemia in women with PCOS (20). Adipose tissue in women with PCOS is characterized by hypertrophic adipocytes and impaired lipolysis and insulin action. The expression and secretion of a wide variety of adipokines implicated in insulin resistance, including adiponectin is also altered in women with PCOS (21). Adiponectin exerts insulinsensitizing properties by stimulating fatty acid oxidation and suppressing hepatic gluconeogenesis, and a dysregulation of adiponectin has been implicated in the pathogenesis of insulin resistance (22). Our findings showed that serum adiponectin levels were significantly lower in women with PCOS as compared with those BMI-matched controls. This result agrees with previous study which found that adiponectin levels in nonobese women with PCOS were significantly lower than those in BMI-matched controls (18). Further study support these results (23) which suggest that decrease adiponectin levels in women with PCOS might be a result of increasing IR in these patients. Furthermore, family history of PCOS and IR were also significantly associated with lower adiponectin levels. $\square$ Increasing evidence suggests that genetic factors play an important role in the pathogenesis of PCOS. Interestingly, prevalence of PCOS in South East Asians settled in United Kingdom was $52 \%$, which is an $18 \%$ higher

rate than the native population, suggestive of some genetic predisposition of PCOS among certain races (24). In addition to familial clustering of PCOS in first degree relatives (25), it has been shown that the pre-pubertal daughters with normal
BMI, of women with PCOS, manifest with disturbed metabolic profile including hypoadiponectenemia and hyperinsulinemia compared to daughters of healthy women (26), although family history is an important risk factor, environmental triggers are also playing a role, e.g. diet, and exercise. In addition, dysfunctional changes in the metabolism of carbohydrates, insulin action, and steroid hormones have also been implicated $\square$ (23). A systematic review and meta-analysis by Toulis et al., on a sub-analysis by using studies only with PCOS cases and controls matched on BMI, revealed that PCOS women had lower levels of adiponectin after controlling for the potential effects of obesity by BMI matching. This suggests that serum adiponectin levels are not independently determined by the degree of adiposity in women but underlying disease may also have some role. A possible explanation for this finding is that lower adiponectin levels in PCOS women might be a result of increasing IR in these patients (27). $\square$ IR might possibly be a link between lower adiponectin level and development of polycystic ovarian syndrome; however, whether low adiponectin is a cause or a consequence of IR in PCOS remains debated $\square(23)$.

\section{Conclusions:}

Serum adiponectin levels are not independently determined by the degree of obesity in women but underlying disease may also have some role and this may due to insulin resistance in these patients thus determining serum adiponectin may serve as a useful marker in detecting cases of normal weight women with PCOS.

\section{Authors Contributions:}

Study conception, Study design and Critical revision: Rana Ali Hamdi, Nawar Sameer Mohammed, Afraa Mahjoob ALNaddawi.

Acquisition of data analysis, Drafting of manuscript and Interpretation of data: Rana Ali Hamdi, Nawar Sameer Mohammed.

Samples were provided by: Afraa Mahjoob AL-Naddawi. 


\section{References:}

1. Marshall JC and Eagleson CA. Neuroendocrine aspects of polycystic ovary syndrome. Endocrinol Metab Clin North Am 1999; 28(2): 295-324.

2. Legro RS, Barnhart HX and Schlaff WD. Clomiphene, Metformin, or Both for Infertility in the Polycystic Ovary Syndrome. N Engl J Med 2007; 356:551-566.

3. Dunaif A. Insulin resistance and the polycystic ovary syndrome: mechanism and implication for pathogenesis. Endocr Rev 1997; 18:774-800.

4. Hahn S, Tan S, Sack S, Kimmig R, Quadbeck B, Mann K and Janssen OE. Prevalence of the metabolic syndrome in German women with polycystic ovary syndrome. Exp Clin Endocrinol Diabetes 2007; 115:130-135.

5. Scherer PE. Adipose tissue: from lipid storage compartment to endocrine organ. Diabetes 2006; 55(6):1537-1545.

6. Fasshauer $M$ and Paschke R. Regulation of adipocytokines and insulin resistance. Diabetologia 2003; 46:1594-1603.

7. Carmina E, Orio F, Palomba S, Cascella T, Longo RA, Colao AM, Lombardi $G$ and Lobo RA. Evidence for altered adipocyte function in

polycystic ovary syndrome. E J E 2005; 152:389-394.

8. Stefan Nand Stumvoll M. Adiponectin-its role in metabolism and beyond. Horm Metab Res 2002; 34:469-474.

9. Matsubara M, Maruoka Sand Katayose S. Decreased plasma adiponectin concentrations in women with dyslipidemia. $J$ Clin Endocrinol Metab 2002; 87:2764-2769.

10. Kazumi T, Kawaguchi A, Sakai K, Hirano Tand Yoshino G. Young men with high-normal blood pressure have lower serum adiponectin, smaller LDL size, and higher elevated heart rate than those with optimal blood pressure. Diabetes Care 2002; 25:971-976.

11. Weyer C, Funahashi T, Tanaka S, Hotta K, Matsuzawa Y, Pratley RE and Tataranni PA. Hypoadiponectinaemia in obesity and type 2 diabetes: close association with insulin resistance and hyperinsulinemia. J Clin Endocrinol Metab 2001; 86 (5):1930-1935. [IVSL, Pub Med]

12. Diez JJ and Iglesias P. The role of the novel adipocytederived hormone adiponectin in human disease. Eur J Endocrinol 2003; 148(3): 293-300.

13. Chabrolle C, Tosca L and Dupont J. Expression and regulation of adiponectin and its receptors (AdipoR1 and AdipoR2) in the rat ovary. Reproduction 2007; 133:719-731.

14. Ledoux S, Campos DB, Lopes FL, Dobias-Goff M, Palin $M F$ and Murphy BD. Adiponectin induces periovulatory changes in ovarian follicular cells. Endocrinology 2006; 147:5178-5186.

15. Palin MF, Bordignon VV and Murphy BD. Adiponectin and the control of female reproductive functions. Vitam Horm 2012; 90:239-287.

16. Matthews DR, Hosker JP, Rudenski AS, Naylor BA, Treacher DF and Turner RC. Homeostasis model assessment: insulin resistance and beta-cell function from fasting plasma glucose and insulin concentrations in man. Diabetologia1985; 28(7):412-419. [IVSL, PubMed]
17. Mc Tigue K. Screening and interventions for overweight and obesity in adults: a summary of the evidence for the U.S. preventive service task force. Ann Intern Med 2003; 139(11):933-949.

18. Lee H, Oh J-Y and Sung Y-A. Adipokines, insulin-like growth factor binding protein-3 levels, and insulin sensitivity in women with polycystic ovary syndrome. Korean J Intern Med 2013; 28:456-463.

19. Oh JY, Lee JA, Lee H, Sung YA and Chung H. Serum $C$-reactive protein levels in normal-weight polycystic ovary syndrome. Korean J Intern Med 2009; 24:350-355.

20. Bremer AA and Miller WL. The serine phosphorylation hypothesis of polycystic ovary syndrome: a unifying mechanism for hyperandrogenemia and insulin resistance. Fertil Steril 2008; 89:1039-1048.

21. Villa $J$ and Pratley RE. Adipose tissue dysfunction in polycystic ovary syndrome. Curr Diab Rep 2001; 11:179-184. 22. Festa A, D'Agostino R Jr, Howard G, Mykkanen L, Tracy $R P$ and Haffner SM. Chronic subclinical inflammation as part of the insulin resistance syndrome: the Insulin Resistance Atherosclerosis Study (IRAS). Circulation 2000; 102:42-47. 23. Mirza SS, Shafique K, Shaikh A-R, Khan NA and Qureshi MA. Association between circulating adiponectin levels and polycystic ovarian syndrome. J Ovarian Res 2014; 7:18.

24. Rodin DA, Bano G, Bland JM, Taylor K and Nussey SS. Polycystic ovaries and associated metabolic abnormalities in Indian subcontinent Asian women. Clinical Endocrinology 1998; 49(1): 91-99.

25. Crosignani $P G$ and Nicolosi AE. Polycystic ovarian disease: heritability and heterogeneity. Hum Reprod Update 2001; 7:3-7. [IVSL, Pub Med]

26. Sir-Petermann T, Maliqueo M, Codner E, Echiburú B, Crisosto N, Pérez V, Pérez-Bravo F and Cassorla F. Early metabolic derangements in daughters of women with polycystic ovary syndrome. J Clin Endocrinol Metab 2007; 92(12):46374642. [IVSL, Pub Med]

27. Toulis KA, Goulis DG, Farmakiotis D, Georgopoulos NA, Katsikis I, Tarlatzis BC, Papadimas I and Panidis D. Adiponectin levels in women with polycystic ovary syndrome: a systematic review and a meta-analysis. Hum Reprod Update 2009; 15(3):297-307. [IVSL, Pub Med. 